\title{
It is time to change our cultural context. Invited commentary on ... Evaluation of England's Time to Change programme
}

Bruce G. Link

\section{Summary}

The Time to Change campaign in England has attempted to change attitudes to mental illness at population level. The concept of cultural context is introduced to look at how mental illness functions in society and whether any change in the current context is feasible.

\section{Declaration of interest}

None.
Both the Time to Change programme against stigma and discrimination and its evaluation are focused on the right goal population-level changes in knowledge, attitudes and behaviours in the general public and in key groups of interest such as employers, mental health professionals and people in treatment for mental illnesses. ${ }^{1}$ The goal is enormously ambitious and extraordinarily difficult to tightly evaluate - but it is the right goal.

\section{Cultural context of mental illness}

The aspects of knowledge, attitudes and behaviours that Time to Change seeks to alter form what we have called a 'cultural context.' In a very deep sense cultural conceptions become the way all of us have of thinking about the issue. They constitute what the general public and key interests groups think about what mental illness is, what people with mental illness are like, what causes mental illnesses, what should be done when a person develops a mental illness, how much social distance should be kept from someone with a mental illness, and what the preferred policies to address the problem of mental illness are. As a context, these cultural conceptions become an external reality - something that individuals must take into account when they make decisions and enact behaviours. The idea is that individuals (e.g. people with mental illnesses, caregivers, employers, policy makers) know about cultural conceptions and shape their behaviours to some significant degree to take account of those conceptions no matter what their own knowledge, attitudes and beliefs happen to be.

\section{Impact of cultural context}

For people who develop a mental illness negative cultural conceptions can be poignantly self-relevant, as they may be induced to ask whether and to what extent 'others will look down on me, reject me, simply because I have been identified as having a mental illness'. Then, if an expectation of rejection becomes a part of a person's worldview, that perception can have serious negative consequences. Expecting and fearing rejection, people who have been hospitalised for mental illness may act less confidently and more defensively, or they may simply avoid a potentially threatening contact altogether. ${ }^{3}$

Cultural conceptions are also salient for mental health policy makers. For example, as treatment providers and policy makers make decisions about where to locate a new board and care home for people with serious mental illness, they are likely to include in their considerations the expected response of the neighbourhoods they imagine placing the facility in. Processes such as these have resulted in a clustering of board and care facilities in neighbourhoods that do not have the clout to exclude such facilities, thereby creating what have been called 'psychiatric ghettos. ${ }^{4}$

Finally, imagine for example that, unlike all other illnesses, insurance policies for heart disease (instead of mental illnesses) were capped at lower levels of compensation and included higher co-pays, as mental illnesses currently are in the USA. ${ }^{5}$ Despite the fact that a rationale could be conjured for such a policy, given that heart disease is influenced by behaviours people can control, such as sedentary lifestyle, fatty diet and smoking, an insurance policy disadvantaging heart disease is unimaginable in the current cultural context. It is in these and many other ways that the cultural context has a broad and often powerful influence on the life circumstances of people with mental illnesses.

\section{Effecting population-level change}

But this is not the final reason that Time to Change and its evaluation are appropriately focused on population-level change. Without change at this level, even apparently effective individuallevel interventions, ones with tight designs, robust effect sizes and tiny $P$-values, are subject to a sharp erosion of effects due to the influence of a broader cultural context that remains unchanged. This is not to say that such individual approaches are fruitless, far from it, rather all of us who implement them must keep the ultimate goal of population change in mind and build our efforts to achieve it.

As is true of almost everything in life the right goal is often an exceptionally difficult one to achieve. This is evident in the nine papers that this commentary accompanies. A sceptic would note that effect sizes are often small and not consistently significant across multiple indicators, ${ }^{6-8}$ response rates in difficult-to-reach groups sometimes low, ${ }^{7}$ positive effects transitory, ${ }^{9}$ effects worse in a subgroup who knew about the campaign than in a group that did not, ${ }^{7}$ and possibilities of confounding that cannot be ruled out by design or analyses are present. ${ }^{6-10}$ These problems are all forthrightly raised in the papers. At the same time, the accumulation of findings across all the papers reveals a pattern of generally positive change as some aspects of public attitudes improve, ${ }^{6,8}$ media reporting is more positive, ${ }^{10}$ service users report less discrimination, ${ }^{7}$ employers are more informed and report policy changes favourable to people with mental health 
problems. ${ }^{11}$ The findings need not have tracked in this generally positive direction but they did and their having done so provides information.

This study will change the landscape of stigma reduction intervention and evaluation efforts going forward. It will do so because of: (1) its focus on population-level change among the general public and key groups of interest, (2) its linking of population-level intervention efforts with population evaluation efforts, and (3) its multi-domain, multifaceted intervention and evaluation. Hopefully, it will spur future work to look beyond the small scale of single, individually based interventions to conceptualise how a multi-pronged intervention might slowly build to have long-lasting effects where they really matter - at the population level. Future researchers may learn from and improve on some of the shortcomings that have been so forthrightly presented in these papers but they will also be changed, and challenged toward a better end, by the ambition and the vision these papers collectively convey.

Bruce G. Link, PhD, Professor of Epidemiology and Sociomedical Sciences, Department of Epidemiology, Columbia University, 722 W 168th St 1610, New York, New York 10032, USA. Email: bgl1@columbia.edu

\section{References}

1 Henderson $C$, Thornicroft G. Introduction to the valuation of the Time to Change programme in England 2008-2011. Br J Psychiatry 2013; 202 (suppl 55): $s 45-8$.
2 Link BG., Angermeyer MC, Phelan, JC. Public attitudes towards people with mental illness. In Oxford Textbook of Community Mental Health (eds G Thornicroft, G Szmukler, KT Mueser, RE Drake): 253-9. Oxford University Press: 2011.

3 Link BG, Cullen FT, Struening E, Shrout PE, Dohrenwend BP. A modified labeling theory approach in the area of the mental disorders: an empirical assessment. Am Soc Rev 1989; 54: 400-23.

4 Arboleda-Florez J. Forensic psychiatry: contemporary scope, challenges and controversies. World Psychiatry 2006; 5: 87-91.

5 Glied S, Frank R. Shuffling toward parity: bringing mental health care under the umbrella. New Engl J Med 2008; 359: 113-5.

6 Evans-Lacko S, Henderson C, Thornicroft G. Public knowledge, attitudes and behaviour regarding people with mental illness in England 2009-2012. Br J Psychiatry 2013; 202 (suppl 55): s51-7.

7 Corker E, Hamilton S, Henderson C, Weeks C, Pinfold V, Rose D, et al. Experiences of discrimination among people using mental health services in England 2008-2011. Br J Psychiatry 2013; 202 (suppl 55): s58-63.

8 Evans-Lacko S, Henderson C, Thornicroft G, Mccrone P. Economic evaluation of the Time to Change anti-stigma social marketing campaign in England 2009-2011. Br J Psychiatry 2013; 202 (suppl 55): s95-101.

9 Friedrich B, Evans-Lacko S, London J, Rhydderch D, Henderson C, Thornicroft G. Anti-stigma training for medical students: the Education Not Discrimination project. Br J Psychiatry 2013; 202 (suppl 55): s89-94.

10 Thornicroft A, Goulden R, Shefer G, Rhydderch D, Rose D, Williams P, et al. Newspaper coverage of mental illness in England 2008-2011. Br J Psychiatry 2013; 202 (suppl 55): s64-9.

11 Henderson C, Williams $\mathrm{P}$, Little K, Thornicroft G. Mental health problems in the workplace: changes in employers' knowledge, attitudes and practices in England 2006-2010. Br J Psychiatry 2013; 202 (suppl 55): 70-6. 